\title{
Los culebrones de la noche: estudio antropológico del comercio informal de combustible en Tumbes
}

\section{The night's big snakes: A study anthropological of the informal trade of fuel in Tumbes}

\author{
Francisco Prado*
}

http://dx.doi.org/10.21503/CienciayDesarrollo.2012.v15i2.09

\section{RESUMEN}

Los "culebrones de la noche" es la denominación simbólica para designar a las unidades vehiculares dedicadas al transporte informal de combustible de Ecuador hacia Perú, conocido con el término coloquial de "los petroleros". Son agrupaciones familiares dedicadas al comercio del carburante que interactúan con las instituciones gubernamentales encargadas de mantener el orden y la seguridad pública, generando un modus vivendi propio de frontera a partir de la tríada de actores del carburante conformado por Aduanas, Policía Fiscal y comerciante informal en el distrito fronterizo de Aguas Verdes (Perú).

Palabras clave: culebrones de la noche, contrabando, comerciante informal, combustible, petrolero, Tumbes.

\section{ABSTRACT}

"The night's big snakes" is the symbolic name used to refer transportation units engaged in the informal transport of fuel from Ecuador to Peru, colloquially knew as "los petroleros", family groups engaged in fuel trade and its interaction with government institutions responsible for maintaining public order and security, generating a typical modus vivendi of border, starting with the triad of the fuel actors conformed by Customs, Police, Prosecutor and the informal trader at the border district of Aguas Verdes (Peru).

Keywords: the night's big snakes, smuggling, informal trader, fuel, oil, Tumbes.

\footnotetext{
* Maestro en Antropología Social, Ministerio Público Medicina Legal-Tumbes. E-mail: Apukiskis@gmail.Com
} 


\section{DESARROLLO ANTROPOLÓGICO}

Los transportistas informales del petróleo viajan en caravana de autos llevando el combustible desde el canal internacional de Aguas Verdes con rumbo a las ciudades de Tumbes, Piura y Chiclayo. En la oscuridad, estas filas de autos representan a "los culebrones de la noche" surcando la Panamericana Norte. En su travesía no hay normas de tránsito, ni patrullero que se interponga, pues, como señalan los propios comerciantes del carburante, "ya todo está arreglado”. Este es el desarrollo del comercio informal del combustible que tiene como inicio el canal internacional de Aguas Verdes y su posterior comercialización en toda la región de Tumbes, siendo la teoría antropológica urbana ${ }^{1}$ directriz de la presente investigación etnográfica, como una apertura a la discusión académica del tema.

Los bajos costos de los carburantes en el Ecuador son el principal atractivo para el comerciante informal peruano. Como referencia, el costo del gas ecuatoriano es de un dólar con sesenta céntimos $(\$ 1,60)$ por balón de 15 kilos, equivalente en moneda nacional a cinco nuevos soles (S/. 5,00). El gobierno ecuatoriano subsidia el gas a cada familia por 45 días; si este se termina antes de los días de subsidio, el costo se incrementa a ocho dólares $(\$ 8,0)$; sin embargo, no todos los ciudadanos consumen el gas, existiendo por ello personas dedicadas al acopio de este carburante, que luego es comercializado en el canal internacional de Huaquillas y Aguas Verdes.

De igual modo sucede con el petróleo, cuyo costo en el Ecuador es de un dólar con treinta y siete céntimos $(\$ 1,37)$, que en moneda nacional son tres nuevos soles; sin embargo, en el Perú cuesta once nuevos soles con cincuenta céntimos. La gasolina súper ecuatoriana cuesta dos dólares con veinte céntimos $(\$ 2,20)$, equivalente en moneda nacional a seis nuevos soles, mientras que en el Perú su precio es de trece nuevos soles con treinta céntimos (gasolina de 90 octanos). La gasolina extra ecuatoriana cuesta un dólar con cuarenta y ocho céntimos $(\$ 1,48)$, equivalente a cuatro nuevos soles con cincuenta céntimos, y en el Perú cuesta diez nuevos soles con setenta céntimos (gasolina de 89 octanos).

Desde la perspectiva EMIC, el combustible es acopiado en los distintos grifos de la provincia del Oro, Ecuador, principalmente en la ciudad de Huaquillas (grifos Mayon en Hualtaco, gasolinera Monterrey, Gasolinera del Sindicato de Choferes de Huaquillas, Entrada 69 y Estación San Luis). Es importante precisar que el propietario de una unidad vehicular que presta el servicio de taxi en Ecuador tiene la dotación y/o permiso para comprar quince galones por día, y al no utilizar todo el combustible, opta por venderlo a los acopiadores de petróleo en el Ecuador. Este petróleo será canalizado a la línea internacional fronteriza del Perú para venderlo luego a los comerciantes informales en nuestro país.

Los vendedores de combustible en Ecuador son básicamente acopiadores del carburante, y se ubican en la margen derecha del canal internacional, lugar conocido como Playita Sur, donde se dan las interacciones de cara a cara, un microcosmos de comportamientos en público entre el acopiador y el comerciante. Erving Goffman $^{2}$ señala la noción de tráfico en lugares públicos urbanos que implica la concepción de naturaleza de identidades individuales resultado de interacciones simbólicas con el otro, en situaciones de encuentro con extraños, siendo el imaginario del acopiador ecuatoriano un personaje muy legal y de porte caballeresco, quien básicamente confía en la palabra del cliente: "Mi palabra es ley", mientras que el peruano tiene el estereotipo coloquial de "cabeceador"; sin embargo, en este microcosmos del negocio del 
carburante muchas veces se trabaja a concesión, es decir, "después de este viaje te pago", motivo por el cual el acopiador ecuatoriano confía en el cliente peruano, registrando sus movimientos en su respectiva agenda, contando así con un staff de clientes honestos. En una conversación informal con Kachaco $\left(\mathrm{Kachaku}^{3}\right)$ (vendedor de combustible en frontera), nos señala: "Mande patrón (estimado amigo), cuando peruano no tiene, nosotros damos al pierde, porque ya sabemos quién paga y quién no, pero si, por ahí, hay quienes se hacen los locos y todavía compran de otro, esos clientes son malos, pero con el tiempo pagan nomás, no ve que de eso comen". (Informante: seudónimo de Kachakito).

Esta realidad nos lleva a formular la hipótesis de trabajo donde la desvirtualización de las instituciones gubernamentales para el caso peruano crea un imaginario colectivo de modus vivendi propio de frontera, a partir de la tríada de actores del carburante conformado por la Policía Fiscal (POLFIS), Aduanas y comerciante informal. Paradójicamente, son sorprendentes los esfuerzos de la Policía Nacional en Tumbes, que resguarda sigilosamente las carreteras de frontera, descuidando incluso el quehacer en la ciudad; sin embargo, crece el contrabando al ritmo de la expansión urbana experimentada por Aguas Verdes en los últimos años, generando nuevos imaginarios y actores sociales.

Louis Wirth en su libro The Ghetto señala la solidaridad étnica de una comunidad y el mantenimiento ideológico de modelos sociales y referentes culturales de la población de origen, manifestándose para el caso de Tumbes en una mirada a los controles de carretera, donde sería una falta grave aventar un objeto contundente a la cabina de un patrullero policial; sin embargo, esta práctica es un elemento simbólico incorporado por los comerciantes del hidrocarburo como una forma de relaciones sociales de pacto en esta selva de símbolos'. Según sostiene Víctor Turner, el novicio policial tendrá que interpretar, dentro de su proceso de socialización de casta, una forma de intercambio recíproco conocida habitualmente como trueque, principio conocido en el mundo andino como el ayni: "tú me das y yo te doy".

Valiéndonos de la vista satelital, la configuración espacial de los vendedores de combustible es la parte lateral derecha del puente internacional (zona este), unión de las avenidas República de Perú y Ecuador: precaria estructura de madera facilitadora del gran déficit fiscal en evasión tributaria para ambas naciones. En el gráfico se remarca con tinta negra el canal divisorio de Perú y Ecuador entre las ciudades de Aguas Verdes y Huaquillas respectivamente, siendo la transversal roja la ruta urbana del tráfico de combustible.

Figura 1. La ruta de ingreso del combustible ecuatoriano al Perú: Huaquillas-Aguas Verdes. Grandes depósitos de combustible ubicados junto a viviendas familiares en la calle Madre de Dios y Jr. Puno. Los comercializadores constantemente son acosados por la autoridad policial bajo la amenaza de informar al Ministerio Público en caso de negarse a cooperar; sin embargo, Playa Sur siempre será el paraíso financiero para la tríada gubernamental, por ser un lugar estratégico de abastecimiento en un poblado de frontera.

La ruta del transporte de combustible a gran escala en Aguas Verdes es el siguiente: se inicia en el canal internacional por la calle Moquegua rumbo al puente Bolsico (río Zarumilla), para dirigirse rumbo al Complejo de Migraciones y oficinas de Aduana. Unos metros antes de Migraciones, existe un desvío conocido como La Curva, donde más de siete caminos los hacen retornar a la Panamericana rumbo a Tumbes. "Entran por La Curva y se van por uno de los siete culebrones ${ }^{4}$ para cruzar Zarumilla y retornar a la Panamericana." (Informante: llenador ${ }^{5}$ de seudónimo Collar ${ }^{6}$ ). Antes del cruce de Puyango (Nuevo Tumbes), hacen un desvío hacia la izquierda, a 
la altura de la institución técnica SENATI, para luego dirigirse a los lugares de almacenamiento en la ciudad de Tumbes. En todo momento, los culebrones de la noche gozan de resguardo estatal en puntos estratégicos, como si fueran máquinas de moneda que hay que alimentar. Es todo un rally petrolero donde los pobladores construyen sus propios rompemuelles como una forma obligada de frenar la velocidad de los culebrones de la noche. Este combustible es el oro líquido que ayuda a muchas familias tumbesinas a frenar el hambre, pues en Tumbes existe la venta de gasolina al menudeo en recipientes de gaseosa y aceite. Son los "grifos al paso", bombas de tiempo en el radio urbano.

Cinco dólares. El conductor de una unidad menor de tres ruedas (triciclo) paga al efectivo gubernamental en el sector de Playita Sur del canal internacional, la suma de cinco dólares por pasar tres tanques de combustible hacia la zona del Terminal Terrestre de Aguas Verdes; del mismo modo, el comerciante ecuatoriano colecta una bolsa común para pagar a la autoridad peruana y así a garantizar su venta. En un triciclo caben tres tanques de petróleo de 58 galones cada uno. Un tanque de petróleo cuesta en el canal internacional de Aguas Verdes la suma de doscientos noventa y cinco nuevos soles $(S / .295,00)$, pero este precio varía por la inestabilidad del dólar.

\section{MODALIDADES DE TRANSPORTE Y ALMACENAMIENTO}

La modalidad de transporte y almacenamiento del combustible ecuatoriano al mercado peruano ha variado durante los últimos años. Si antes el combustible era almacenado en bidones de plástico (pipas) y cilindros, ahora es almacenado en bolsas de plástico y luego en bidones (pipas), tanques y cilindros. En el pensamiento de Oscar Lewis, ${ }^{7}$ esta modalidad obedece a un mecanismo de camullaje que reside en la marginación de grupos periféricos, siendo el caso una búsqueda de evadir los controles aduaneros y policiales de Perú. Además, el uso de las bolsas plásticas de cinco galones optimiza el espacio en el compartimiento vehicular.

La venta de petróleo se da durante las veinticuatro horas del día, todos los días. No hay excepciones. En estos momentos, los comerciantes del carburante en la frontera están acondicionando las bolsas de petróleo en unidades vehiculares; todo esto en el canal internacional. A diario, los ecuatorianos continúan almacenando sus depósitos de combustible. "La autoridad policial de Perú, caballero no mas, tiene que arreglar con nosotros: yo le digo que voy a pasar tres tanques y me cobra $S / .15,00$ nuevos soles (equivalente aproximadamente a 5 dólares). La tarifa por tanque es de S/. 5,00 nuevos soles" (microcomercializador de combustible). Las costumbres deshonestas de sectores de la Policía Nacional de frontera son la principal fuente alimenticia del contrabando, que tiene como efecto la evasión tributaria, accidentes de tránsito, muertos calcinados en plena Panamericana Norte del país. "El choque entre un automóvil repleto de combustible ecuatoriano de contrabando y una combi dejó ayer tres muertos y cuatro heridos, uno de ellos de gravedad. El hecho ocurrió en la Panamericana Norte, a la altura del cruce al aeropuerto de Tumbes" ${ }^{8}$ Noticias como esta cubren titulares de portada en la prensa local tumbesina despertando un interés coyuntural efímero.

\section{PARADERO FINAL DEL COMBUSTIBLE:} CHICLAYO

"Por viaje gano seiscientas lucas; más que un profesional”. Son las expresiones del conductor que realiza dos a tres viajes por semana llevando petróleo de Aguas Verdes hacia Chiclayo. "Llevo 40 bolsas de petróleo en mi carro. Este carrito desarrolla buena velocidad en la pista, no ve que tiene 8 cilindros. La mayoría de los trabajadores del fletero paran tomando. Algunos saben apro- 
vechar y hacen su casa, otros viajan y malgastan su plata tomando en las cantinas". (Informante: La Burra. $)^{9}$

El paradero final del combustible informal es Chiclayo. Los costos en esta ciudad son el doble del costo en frontera, y, según las indagaciones del caso, existen familias organizadas dedicadas al acopio del combustible: "En Chiclayo nos pagan nueve cincuenta a diez nuevos soles por galón, porque en un viaje de Aguas Verdes hacia Chiclayo llevamos tres tanques por auto y esto se vende como pan caliente. De todos los gastos, entre el aforo ${ }^{10}$ y comida, nos quedan seiscientos a setecientos nuevos soles por viaje, y se gana esta suma en solo dos días (ida y vuelta); es rentable. Nosotros hacemos tres viajes por semana; a veces, esto varía por los constantes operativos". (Informante $\left.\mathrm{N}^{\circ} 01.\right)^{11}$

$\mathrm{Al}$ respecto de los viajes en caravana (culebrones de la noche), se cuenta con información de otra persona dedicada al transporte de petróleo informal. "Otros, como Ferna ${ }^{12}$ y los Soñas llevan en carros más grandes y ganan más. Ferna lleva en sus camiones grandes por Socapan pasando por la quebrada Fernández para llegar a Máncora. Tiene tanques de plástico acondicionado. Él tiene todo arreglado con la policía y ya no pasa por carpitas". ${ }^{13}$ (Informante No 02.) ${ }^{14}$

No solo en Chiclayo se vende combustible de Aguas Verdes, sino también en las ciudades del trayecto; al respecto, se tiene la siguiente entrevista: "Los que compran son señores que esperan en el Terminal Terrestre, y ellos tienen depósitos de combustible en su casa. En Chiclayo se vende el galón a diez nuevos soles, y cuando hay mucha competencia se vende a nueve cincuenta. El que quiere ganar menos, lo vende antes de Chiclayo, en Maderitos o en el Barrio de la Brea de Sullana. En Talara se vende a los mismos grifos de la ciudad". (Informante: No 03.)
Del mismo modo, en las entrevistas realizadas a los propios microcomercializadores de petróleo informal, estos señalan: "Nosotros vendemos a todos los grifos de Tumbes; por eso es que todos los grifos de Tumbes venden combustible ecuatoriano; si no, date una vuelta en la madrugada por los grifos Girasol, Romero, El Bosque y otros. Si no abastecemos nosotros, lo abastecen los Soñas y Felucos" (informante: La Burra). Se observó, durante el trabajo de campo, que las camionetas nuevas Nissan Frontier de la Policía de Aguas Verdes, Zarumilla, Tumbes y Zorritos reportan combustible del microcomercializador de petróleo informal utilizando embudos grandes con malla fina para llenar el tanque de combustible.

\section{REACCIÓN FRENTE A LOS OPERATIVOS}

Los estudios de campo refieren al grupo familiar "Los Huamán" como una horda importante en el comercio informal del combustible; sin embargo, a la fecha, ellos ya cambiaron de rubro y comercializan productos de lencería de Ecuador hacia Perú. "Sí, la señora Ada vende combustible en su casa de la Navarrete, lo hace solo en botellitas porque "Los Huamán" ahora ya venden ropas interiores. Llevan a Chiclayo y los venden al por mayor en el Mercado Modelo de la Fronterita". (Informante $\mathrm{N}^{\circ} 04$.)

Por información de los propios tramitadores, ${ }^{15}$ esta mercadería no es declarada ante Aduanas, pero pasa sin mayor control. "La merca pasa nomás, porque todo ya está arreglado. Solo cuando hay operativo con fiscal, ahí para la cosa, pero eso es un rato nada más". (Tramitador: Alfonso.)

La "mama Soña"16 es el personaje estigmatizado que ocupa un liderazgo dentro del imaginario colectivo, por ser la principal organizadora y agrupadora de personas para boicotear las operaciones policiales, en la lucha por impedir el 
decomiso del petróleo informal por parte de la entidad del estado peruano. "Si llegase a ocurrir alguna intervención policial y/o fiscal en plena carretera, la señora América es la Soña, que se encarga de recolectar gente y trasladarla al lugar del operativo para impedir que se les quite la merca. Ella reúne a los vagos de Tumbes y Zarumilla (La Curva y Buenos Aires)". (Informante: La Burra, distrito La Cruz.)

\section{EL COMERCIO EN EL PUENTE INTERNACIONAL}

El Puente Internacional Huaquillas-Aguas Verdes es un emporio comercial que da dinamismo a Huaquillas y Aguas Verdes. Antes de la dolarización ecuatoriana, los comerciantes peruanos adquirían mercaderías ecuatorianas, porque la moneda nacional se cuadruplicaba en su valor frente al Sucre ecuatoriano. Luego de la dolarización, el panorama comercial se invierte a favor del Ecuador, donde la moneda peruana se desmultiplica frente al dólar. Si antes el comerciante peruano compraba mercadería ecuatoriana, ahora el ecuatoriano adquiere mercadería peruana. Los productos ecuatorianos no declarados en Perú y que dejan grandes ganancias al comerciante peruano, son sin duda la venta del gas, gasolina y petróleo.

La dolarización ecuatoriana reconfiguró el panorama económico entre Perú y Ecuador, dando un giro de 180 grados a favor del Ecuador. Por ello, la compra de grandes cantidades de mercadería tiene que ser declarada en las oficinas de la Corporación Aduanera Ecuatoriana y la Superintendencia Nacional de Aduanas en el Perú. Muchas veces, estos controles son burlados por los comerciantes peruanos y ecuatorianos, dando origen a la cadena del contrabando ${ }^{18}$ en el Perú.

\section{MARCO LEGAL PERÚ-ECUADOR}

Aguas Verdes es el distrito fronterizo de Perú con Ecuador en la provincia de Zarumilla, Región
Tumbes, mientras que Huaquillas es el cantón fronterizo del Ecuador con Perú. En la intersección de Huaquillas y Aguas Verdes se encuentra el Puente Internacional de Perú y Ecuador.

El tránsito de personas y vehículos entre Huaquillas y Aguas Verdes está regulado por el Reglamento de Tránsito de Personas y Vehículos Terrestres del Convenio entre Ecuador y Perú sobre el Tránsito de Personas, Vehículos, Embarcaciones Fluviales y Marítimas y Aeronaves, suscrito en la ciudad de Tumbes a los doce días del mes de julio del 2002, en el marco del Tratado de Paz de Brasilia; razón por la cual los ciudadanos peruanos y ecuatorianos no puedes ser controlados ni detenidos por las fuerzas del orden de ambos países.

El ciudadano de a pie ecuatoriano-peruano tiene el derecho de transitar libremente por las calles de Huaquillas (Ecuador) y Aguas Verdes (Perú), ${ }^{19}$ por existir "La Zona de Libre Tránsito", comprendida en las intersecciones de la Oficina de Control en la Dirección de Migración en el Ecuador y la Dirección General de Migraciones y Naturalización en el Perú; por ello, las fuerzas del orden policial y militar de ambos países están llamadas a proteger y cuidar a sus ciudadanos dentro de la Zona de Libre Tránsito, donde es posible además comprar mercadería personal sin restricción alguna, y cuando se trata al por mayor, la misma se tiene que declarar ante las instancias correspondientes.

\section{PRODUCTOS DE CONTRABANDO ENTRE PERÚ ECUADOR}

Dentro de los productos ecuatorianos preferidos por el comerciante peruano está la compra de agroquímicos, artículos de cama "Sábanas Nancy" y medicamentos. En el sector de Pesquería ${ }^{20}$ está la compra del tuno, pota, tilapia y el perico chico del Ecuador, mientras que el calamar, lenguado, perico grande y el tollo 


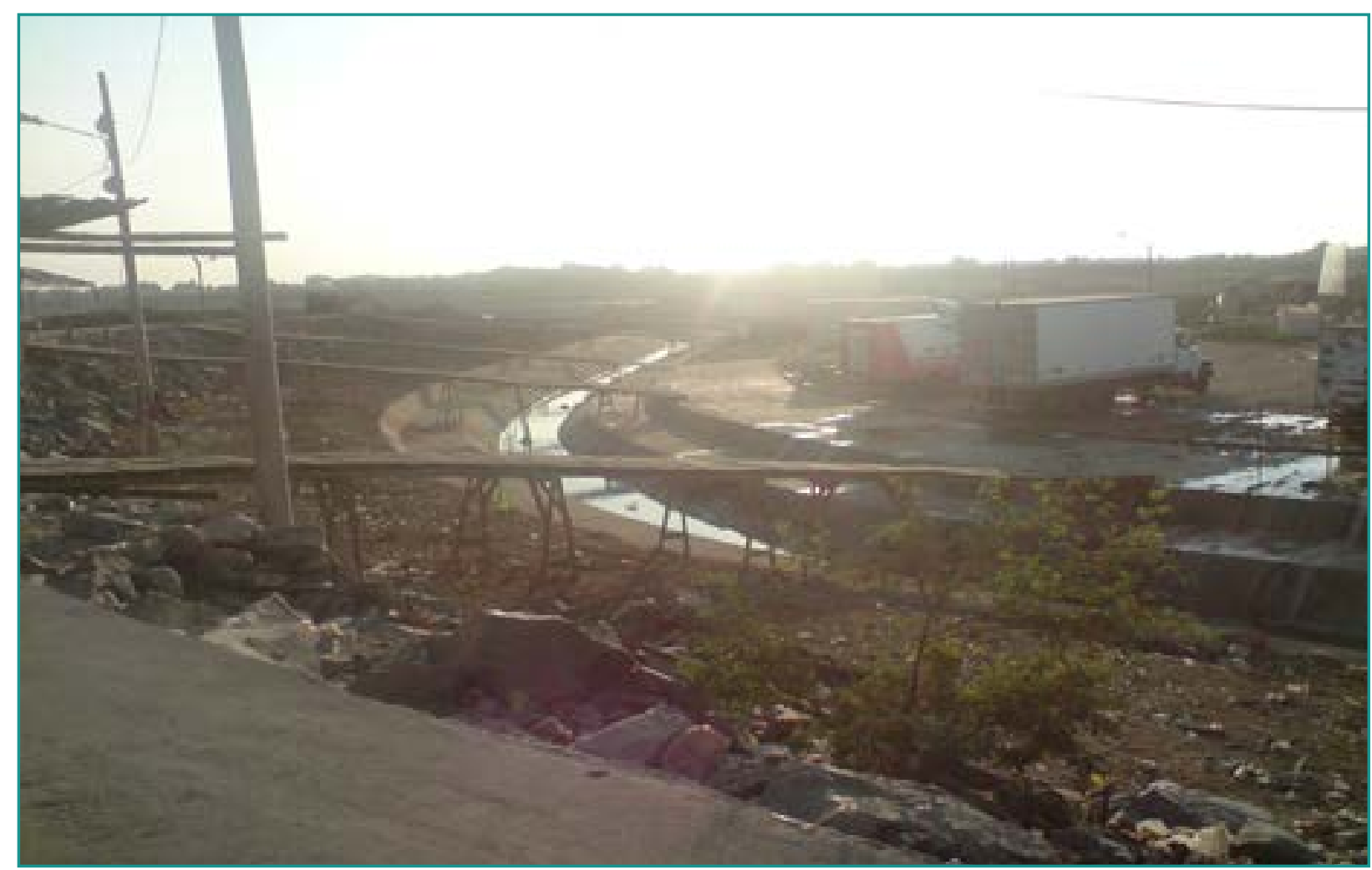

Fotografía 1. Foto panorámica desde lado ecuatoriano: canal internacional en Playa Sur, donde se aprecian los puentes provisionales de madera para el traslado de pescado ${ }^{17}$ entre Perú y Ecuador.

los exporta el Perú; también se tiene el palo de Guayaquil o bambú, entre otros. Los productos señalados son en su gran mayoría declarados ante la Superintendencia Nacional de Aduanas del Perú (información de campo). Aguas Verdes es una ciudad peruana de comercio internacional con Ecuador, dividida por las siguientes zonas comerciales: zona de venta de ropa, de venta de limón, de venta de cebolla, de venta de chatarras, de venta de combustible y gas, y zona de venta de pescado.

A modo de conclusión, los culebrones de la noche son el resultado de una práctica desvirtualizada del vivir en frontera, siendo el presente estudio una apertura a la discusión académica desde la perspectiva EMIC.

\section{CITAS}

1 La antropología urbana como campo espe- cializado de las ciencias sociales surge básicamente en Norteamérica e Inglaterra con los teóricos de la Escuela de Chicago y Manchester. Los trabajos de investigación de la antropología urbana se centran básicamente en estudios de grupos sociales, territorios (área cultural), segregaciones raciales y culturales, subculturas o subuniversos, como la obra de Trasher en su libro The Gang 1927, donde describe la evolución de las pandillas de Chicago a clubs deportivos respetables. Mientras tanto, los ideólogos de la Escuela de Manchester estudian la ciudad como un modo de vida más que como entidad física y espacial desde la teoría de la aculturación.

2 Idea extraída de José Ignacio Homobono en Antropología urbana: itinerarios teóricos, tradiciones nacionales y ámbitos temáticos en la exploración de lo urbano. p. 18.

3 Término quechua para referirse al soldado.

4 Término utilizado por los lugareños para re- 
ferirse al camino con muchas curvas.

5 Llenador es un término asignado a la persona que se dedica al pase del combustible en la línea fronteriza Perú-Ecuador.

6 Individuo con historia rica en requisitorias que trabaja en Aguas Verdes como estibador y extorsionador. Al momento de la entrevista informal, Collar contaba con muchos cortes en la parte frontal del antebrazo, fruto de su larga historia delictiva.

7 Autor del libro Antropología de la Pobreza, donde describe casos familiares que analógicamente corresponderían a muchas familias tumbesinas dedicadas a la comercialización del combustible.

8 Domingo 01 de julio, 2012. Diario Perú 21. "Tres mueren calcinados en choque".

9 Transportista informal de petróleo "Petrolero”, del distrito de La Cruz (Tumbes).

10 Aforo es un término utilizado por los "petroleros" para referirse al pago del policía en cada intervención de carretera.

11 Los informantes № 01, 03 y 04 pidieron la reserva de su identidad.

12 Nombre de una organización familiar dedicada al transporte del combustible informal.

13 Control aduanero.

14 Florean Maza Morante.

15 El tramitador es la persona que se encuentra en la oficina de Migraciones y Aduanas (Complejo de Zarumilla), que se encargan de asesorar y guiar comerciantes de Perú y Ecuador.

16 Horda familiar dedicada al tráfico de combustible en la ciudad de Tumbes.

17 López Asalde Manuel María es el Presidente de la Asociación de Estibadores Hidrobiológicos y Agropecuarios Virgen de Guadalupe; existe también otra asociación denominada Estibadores Unidos por la Paz, con domicilio legal en el Barrio Playa Sur s/n de Aguas Verdes.

18 Se conoce como contrabando a la mercadería no declarada en las instancias correspondien- tes, es decir, no hay pago de los impuestos de ley.

19 La Zona de Libre tránsito está comprendida entre la ubicación del Centro Nacional de Atención de Frontera CENAF y el Centro de Binacional de Atención de Frontera /CEBAF en el nuevo eje vial.

20 En Aguas Verdes existen dos asociaciones de estibadores: Asociación de Estibadores Hidrobiológicos y Agropecuarios Virgen de Guadalupe y Asociación de Estibadores Unidos por la Paz.

Dentro de los productos ecuatorianos preferidos por el comerciante peruano está

\section{REFERENCIAS BIBLIOGRÁFICAS}

1. Hannerz, Ulf (1986). Exploración de la ciudad. Hacia una antropología urbana. México: Fondo de Cultura Económica.

2. Wirth Lorig, L. (1928). The Ghetto. Chicago: University of Chicago Press. Zane Millar, L. (May 1992). Louis Wirth, the Ghetto, the City, and "Integration", en: Journal of Urban History. Vol. 18, № 3.

3. Lewis, Oscar (1961). Antropología de la Pobreza: cinco familias. México: Fondo de Cultura Económica.

4. Glifford Geertz, J. (1987). La interpretación de las culturas. México: Editorial GEDISA.

5. Turner Witter, V. (1990). La selva de los simbolos: aspectos del ritual Ndembu. Madrid: siglo XXI. 


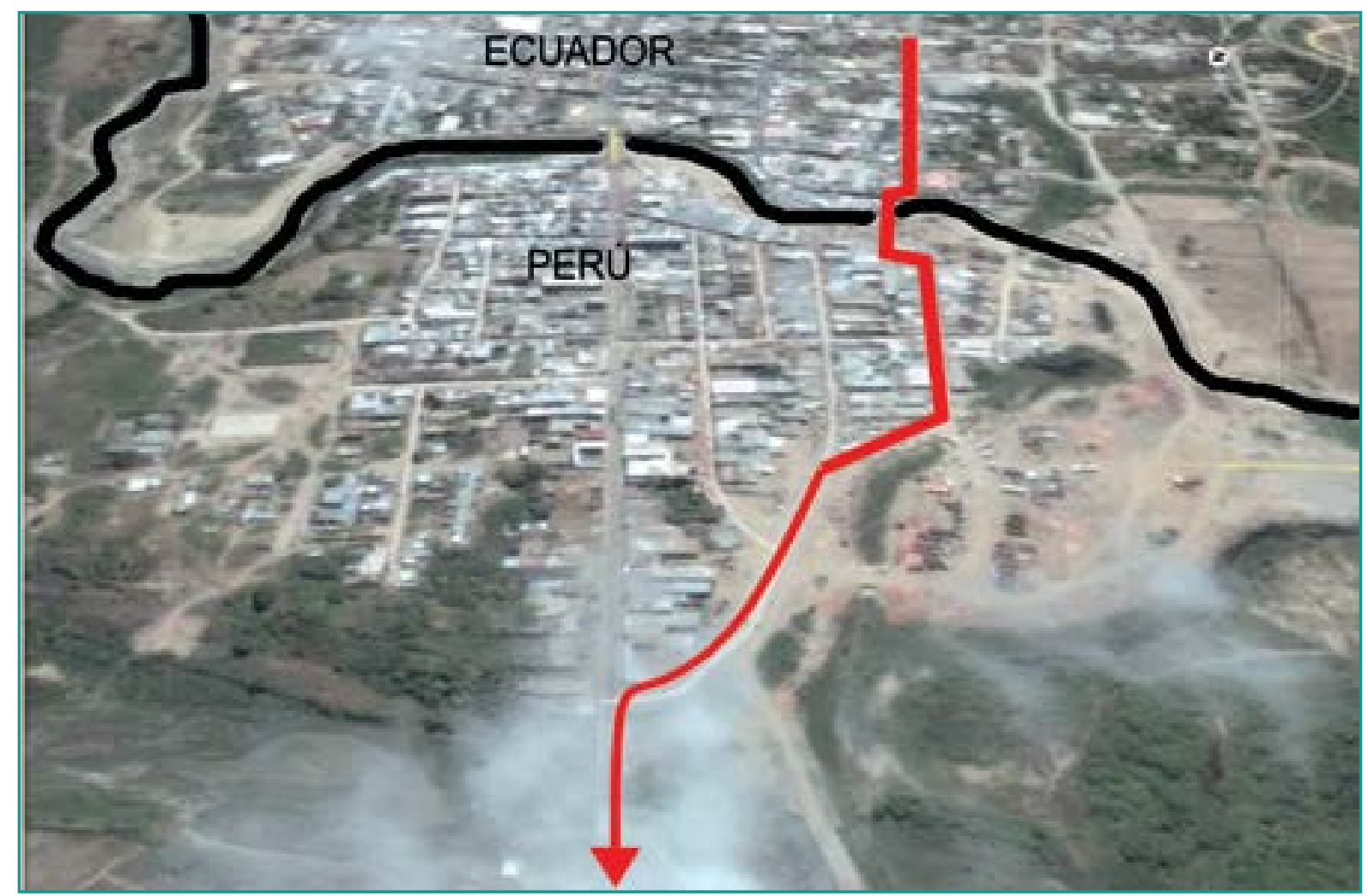

Fotografía 2. Línea divisoria entre Ecuador y Perú. Ruta de ingreso del combustible ecuatoriano al Perú: Huaquillas-Aguas Verdes

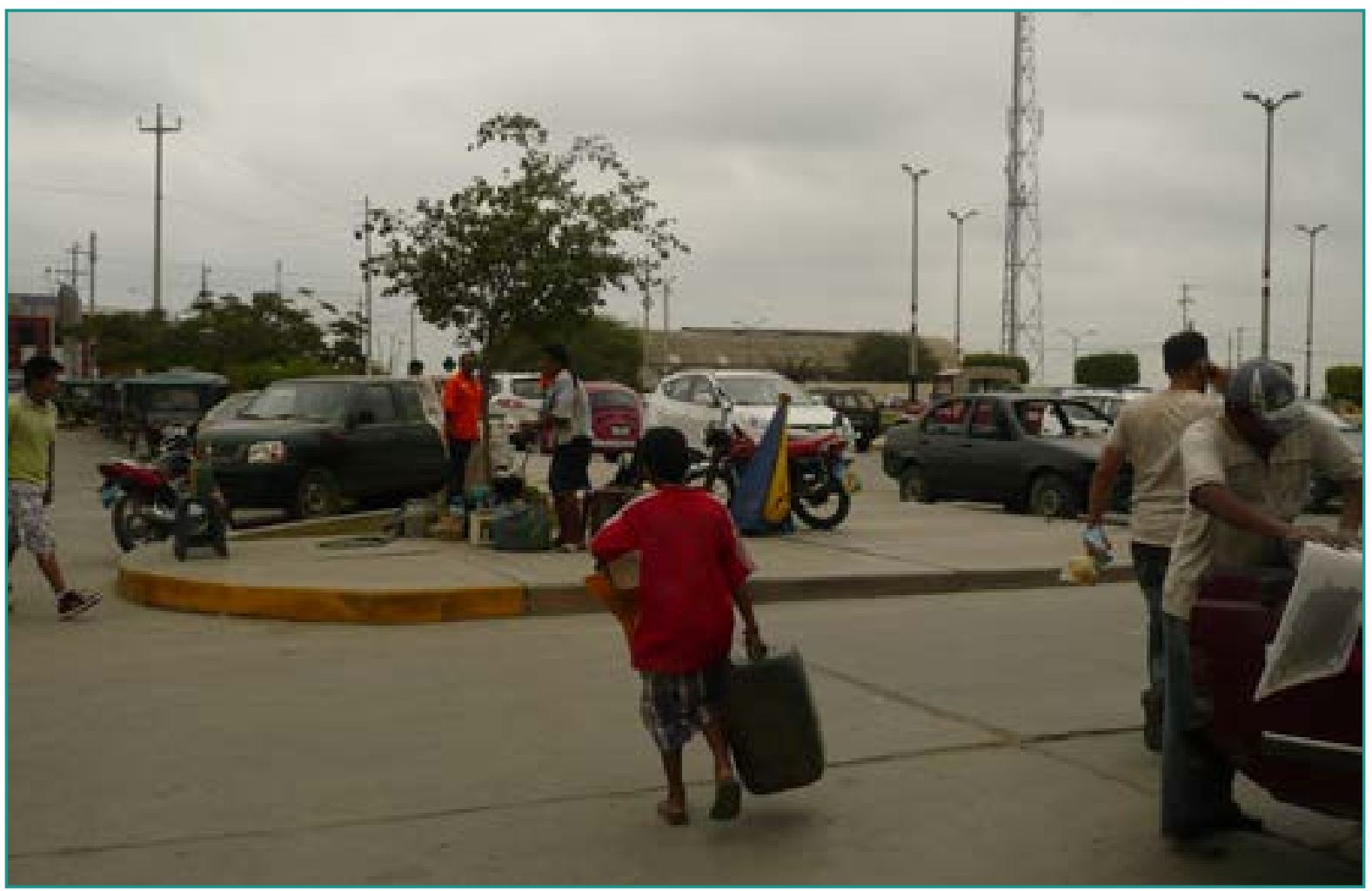

Fotografía 3. Venta de combustible en plena vía pública-Plaza Miguel Grau- Nuevo Tumbes. 


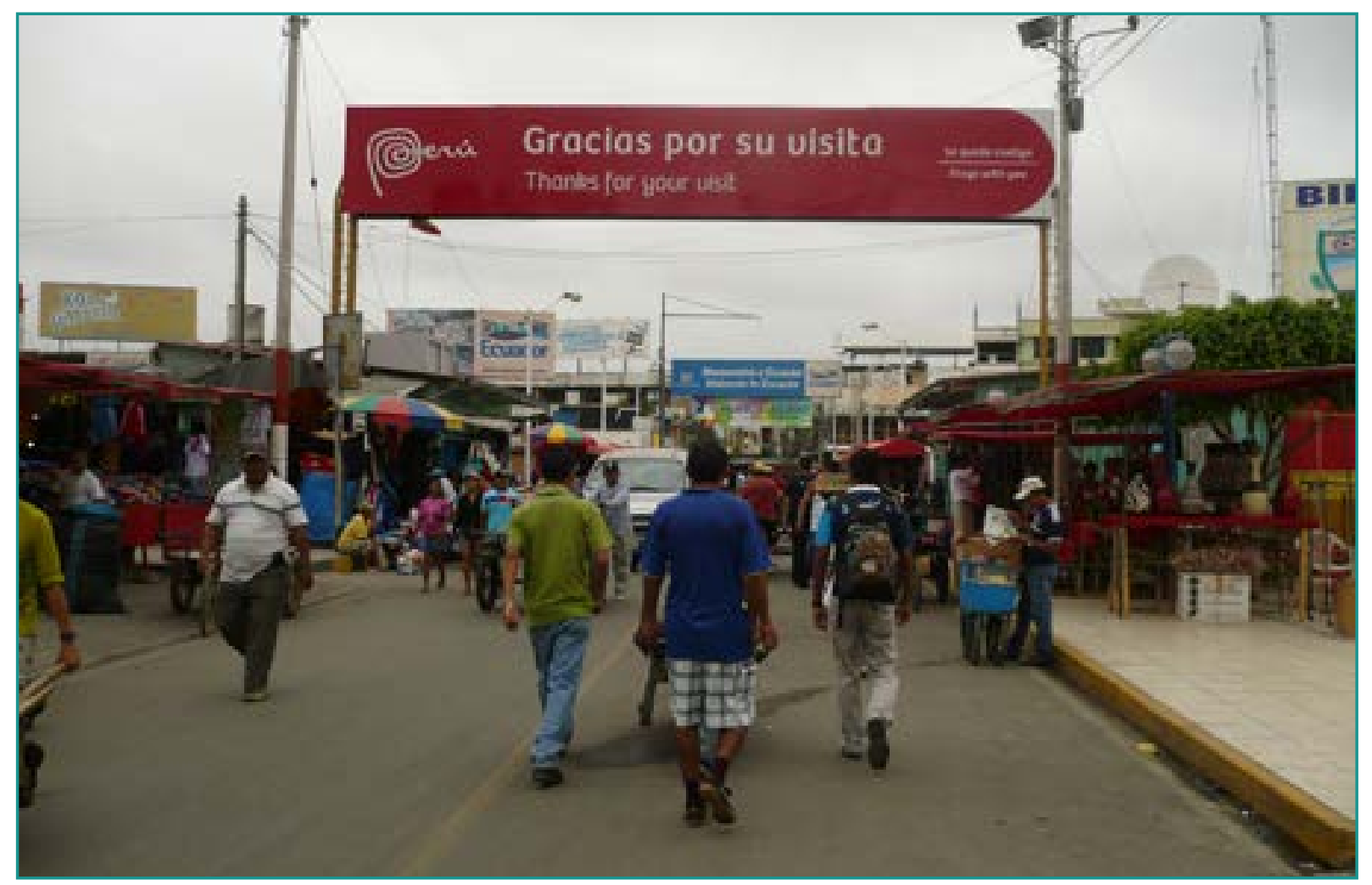

Fotografía 4. Vista panorámica del Puente binacional Perú-ecuador.

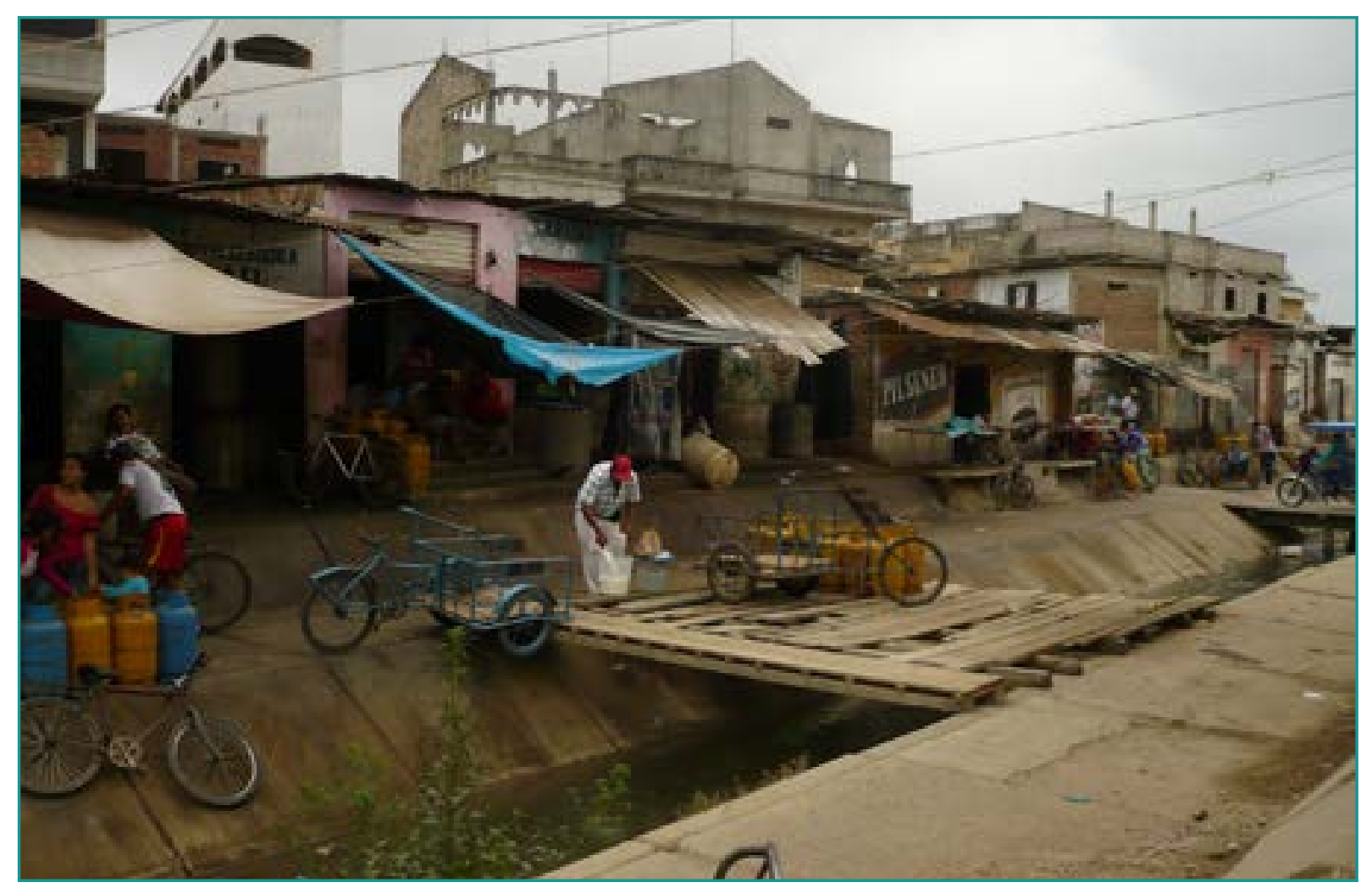

Fotografía 5. Vista panorámica de la venta del carburante en lado ecuatoriano. Primer puente: venta de balones de gas de $15 \mathrm{~kg}$. Segundo puente: transporte del petróleo y gasolina en unidades menores motocar. 